\title{
Assessment of Length of Maternal Cervix between 18 and 24 weeks of Gestation in a Low-Risk Brazilian Population
}

\section{Avaliação do comprimento do colo uterino materno entre 18 e 24 semanas de gestação em uma população brasileira de baixo risco}

\author{
Soraya Gomes de Amorim Andrade ${ }^{1}$ Fernando Moreira de Andrade ${ }^{1}$ Edward Araujo Júnior ${ }^{1}$ \\ Cláudio Rodrigues Pires ${ }^{2}$ Rosiane Mattar ${ }^{1}$ Antonio Fernandes Moron ${ }^{1}$ \\ 1 Department of Obstetrics, Escola Paulista de Medicina, Universidade \\ Federal de São Paulo (EPM-UNIFESP), São Paulo, SP, Brazil \\ Address for correspondence Edward Araujo Júnior, PhD, Rua \\ Botucatu, 740, 04023-062, Vila Clementino, São Paulo, SP, Brazil \\ ${ }^{2}$ Centro de Referência no Ensino do Diagnóstico por Imagem \\ (e-mail: araujojred@terra.com.br). \\ (CETRUS), São Paulo, SP, Brazil
}

Rev Bras Ginecol Obstet 2017;39:647-652.

\begin{abstract}
Purpose To determine cervical biometry in pregnant women between 18 and 24 weeks of gestation and the ideal mode of measurement of cervical length in cases of curved and straight cervical morphology.

Methods The uterine cervices of 752 low-risk pregnant women were assessed using transvaginal ultrasound in a prospective cross-sectional study. In women with straight uterine cervices, cervical biometry was performed in a continuous manner. In women with curved uterine cervices, the biometry was performed using both the continuous and segmented techniques (in segments joining the cervical os). Polynomial regression models were created to assess the correlation between the cervical length and gestational age. The paired Student $t$-test was used to compare measuring techniques. Results The cervical biometry results did not vary significantly with the gestational age and were best represented by linear regression $\left(R^{2}=0.0075\right.$ with the continuous technique, and $R^{2}=0.0017$ with the segmented technique). Up to the $21^{\text {st }}$ week of gestation, there was a predominance of curved uterine cervix morphology (58.9\%),

Keywords

- gestation

- uterine cervix

- biometry

- morphology

- transvaginal ultrasound whereas the straight morphology predominated after this gestational age (54.2\%). There was a significant difference between the continuous and the segmented measuring methods in all the assessed gestational ages $(p<0.001)$.

Conclusion Cervical biometry in pregnant women between 18 and 24 weeks was represented by a linear regression, independently of the measuring mode. The ideal measuring technique was the transvaginal ultrasound performed at a gestational age $\geq 21$ weeks.
\end{abstract}

received

April 4, 2017

accepted

September 9, 2017

published online

November 27, 2017
DOI https://doi.org/

10.1055/s-0037-1608617. ISSN 0100-7203.
Copyright $(2017$ by Thieme Revinter

Publicações Ltda, Rio de Janeiro, Brazil
License terms

c) $\oplus \triangleq \$$ 


\begin{abstract}
Resumo
Descritores

- Gestação

- Colo uterino

- Biometria

- Morfologia

- Ultrassom transvaginal

Objetivo Determinar a biometria cervical em gestantes entre a $18^{\mathrm{a}}$ e $24^{\mathrm{a}}$ semanas, e ainda a forma ideal de mensuração do comprimento do colo uterino em casos de morfologias curva e reta.

Métodos Foram realizadas avaliações ultrassonográficas via vaginal dos colos uterinos de 752 gestantes de baixo risco em um estudo prospectivo transversal. Nos colos uterinos retos a biometria cervical foi feita de forma contínua, enquanto nos colos uterinos curvos, a biometria foi realizada de duas formas, contínua e fracionada (em segmentos unindo os orifícios do colo). Para avaliar a correlação entre o comprimento do colo uterino e a idade gestacional, foram criados modelos de regressão polinomial. Para se comparar a técnicas de medida do colo uterino, utilizou-se o teste t-Student pareado.

Resultados A biometria do colo uterino não variou de forma significativa com a idade gestacional, sendo melhor representada por uma regressão linear $\left(R^{2}=0,0075\right.$ na forma contínua, e $R^{2}=0,0017$ na forma fracionada, respectiva-

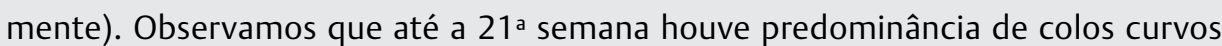
$(58,9 \%)$, porém após esta idade gestacional a morfologia retilínea predominou $(54,2 \%)$. Houve diferença estatisticamente significativa entre a forma de mensuração contínua e fracionada em todas as idades gestacionais avaliadas $(p<0,001)$. Conclusão A expressão da biometria cervical em gestantes entre 18 e 24 semanas é praticamente uma reta, independente da forma de mensuração. A forma ideal de medida é por ultrassonografia transvaginal realizada em idade gestacional $\geq 21$ semanas.
\end{abstract}

\section{Introduction}

Prematurity is a major cause of perinatal morbidity and mortality. A short uterine cervix is a predictor of premature birth; therefore, its morphological and biometric assessment is important. ${ }^{1,2}$

Cervical assessment is performed by clinical examination and ultrasound. ${ }^{3}$ Bidigital examination requires dilation of the internal cervical os. It is, therefore, a subjective assessment of the cervix, and it can underestimate the actual cervical length by up to $12 \mathrm{~mm} .{ }^{4}$ The most accurate cervical assessment method is the transvaginal ultrasound, which allows adequate observation of the internal and external cervical os and the endocervical canal, with a biometric precision of $\sim 100 \% .{ }^{5}$ The morphological and biometric study of the uterine cervix should be performed from the $14^{\text {th }}$ week of gestation onward because the ultrasonographic differentiation between the cervix and the lower uterine segment using ultrasound becomes difficult before this gestational age. $^{6}$

There is no consensus among authors regarding the value of cervical length that is considered short and the associated risk for premature labor, the reported values varying between 20 and $25 \mathrm{~mm}^{7-9}$ The importance of cervical biometry in screening patients for preterm labor has been highlighted in several publications; however, studies that have investigated the techniques of cervical measurement are rare. The evaluation of uterine cervical morphology is important because it is technically more difficult to measure cervical length in cases of curved uterine cervices, and the best measuring method in these cases is still controversial. ${ }^{10}$

When the uterine cervix has a straight morphology, its measurement is performed in a continuous manner, that is, along the cervical canal. When the cervix is curved, the biometric measurement may be performed in two ways: (1) in a continuous manner, for example, from the internal os to the external os of the cervix; and (2) in a segmented manner, such as, by dividing the cervix into segments, with the measured cervical length being the sum of these segments. ${ }^{10,11}$

Routine evaluation of uterine cervical length during the second trimester morphological ultrasound is an important method to screen for preterm labor because most women do not have risk factors. ${ }^{12,13}$

The objectives of the present study were to assess the cervical biometry between 18 and 24 weeks of gestation and to analyze the influence of uterine cervical morphology (straight or curved) on the measuring technique for cervical length, for example, segmented or continuous.

\section{Methods}

This was a prospective and cross-sectional study of transvaginal ultrasound assessment of the uterine cervical biometry in pregnant women between 18 and 24 weeks of gestation. The patients were recruited at a diagnostic imaging training center and at a fetal medicine outpatient center, both located in 
the city of São Paulo, Brazil. This study was approved by the Research Ethics Committee of the institution and a signed informed consent was obtained from patients who agreed to participate voluntarily. The patients received an explanation on the importance of assessing the uterine cervix and its relationship with premature labor and associated complications.

The inclusion criteria were singleton pregnancies between 18 and 24 weeks of gestation, with gestational age determined by the date of last menstruation and confirmed by ultrasound performed up to the $13^{\text {th }}$ week. The exclusion criteria were previous history of preterm labor; recurrent miscarriage (two or more consecutive miscarriage); cervical manipulation, such as conization, cervical amputation and cerclage; previous history of loop electrosurgical excision procedure (LEEP)/large loop excision of the transformation zone (LLETZ); uterine and fetal malformations, and increase or decrease of amniotic fluid index (AFI) (oligohydramnios AFI $<5 \mathrm{~cm}$ or polyhydramnios - AFI $>25 \mathrm{~cm}$ ).

After undergoing the second semester morphological ultrasound, the pregnant women were instructed to completely empty their bladders and remain in the gynecological position to undergo transvaginal examination with an endocavity transducer of 5-6.5 MHz and an opening angle greater than $120^{\circ}$. All the ultrasound examinations were performed with a Logiq P5 apparatus (General Electric Healthcare, Milwaukee, WI, USA). The transducer was covered with a lubricant and gel-free condom and was inserted into the anterior vaginal fornix. This method allowed observing the morphology of the uterine cervix (straight or curved), the internal and external os of the cervix, and the endocervical canal surrounded by the cervical gland area. Continuous biometry was performed for straight uterine cervices, in which the examiner placed one measuring caliper in the internal os and another in the external os ( - Fig. 1A). For curved uterine cervices, the examiner used two measurement techniques; the continuous technique as described above and the segmented technique, in which the first measuring caliper was placed in the internal cervical os, the second caliper was placed at the beginning of the cervical bend, and the last caliper was placed in the external cervical os (-Fig. 1B). The sum of these segments was described as the length of the uterine cervix. All measurements were performed by only two experienced examiners.

The qualitative variables (gestational age, number of gestations, number of vaginal deliveries, maternal age, ethnicity, smoking, curved cervix, and straight cervix) were expressed as absolute and relative values, whereas the quantitative variables (cervical length measured by both the continuous and the segmented techniques) were expressed as means, standard deviations (SD), medians, and minimum and maximum values. Polynomial regressions were performed to evaluate the correlation between cervical length and gestational age, and the quality of fit was assessed using the coefficient of determination $\left(\mathrm{R}^{2}\right)$. The measurements of the uterine cervix performed using the continuous and segmented techniques were compared using the paired Student $t$-test. The statistical analysis was performed using the SPSS software version 13.0 (SPSS Inc., Chicago, IL, USA), with the level of significance set at $p<0.05$.

\section{Results}

The assessment included 752 pregnant women at gestational ages between 18 and 24 weeks, with the following distribution: $87(11.5 \%)$ at 18 weeks, $91(12.1 \%)$ at 19 weeks, 86 (11.4\%) at 20 weeks, $84(11.2 \%)$ at 21 weeks, $83(11.0 \%)$ at 22 weeks, 211 (28.1\%) at 23 weeks, and 110 (14.6\%) at 24 weeks. The mean maternal age was $30.3 \pm 5.3$ years (16-42 years); $68.8 \%$ women were white, $51.2 \%$ were primigravidas, and $9.6 \%$ were smokers.

The results of the continuous cervical biometry varied from $38.7 \pm 7.4 \mathrm{~mm}(16-60 \mathrm{~mm})$ at the $18^{\text {th }}$ week to $36.3 \pm$ $7.5 \mathrm{~mm}(12-53 \mathrm{~mm})$ at the $24^{\text {th }}$ week. The results of the segmented cervical biometry varied from $40.2 \pm 7.8 \mathrm{~mm}$ $(16-60 \mathrm{~mm})$ at the $18^{\text {th }}$ week to $38.1 \pm 7.9 \mathrm{~mm}(12-53 \mathrm{~mm})$ at the $24^{\text {th }}$ week. Uterine cervical biometry did not vary significantly with gestational age and was best represented by a linear equation both for the continuous $\left(R^{2}=0.0075\right)$ and the segmented $\left(R^{2}=0.0017\right)$ techniques (-Fig. 2$)$.
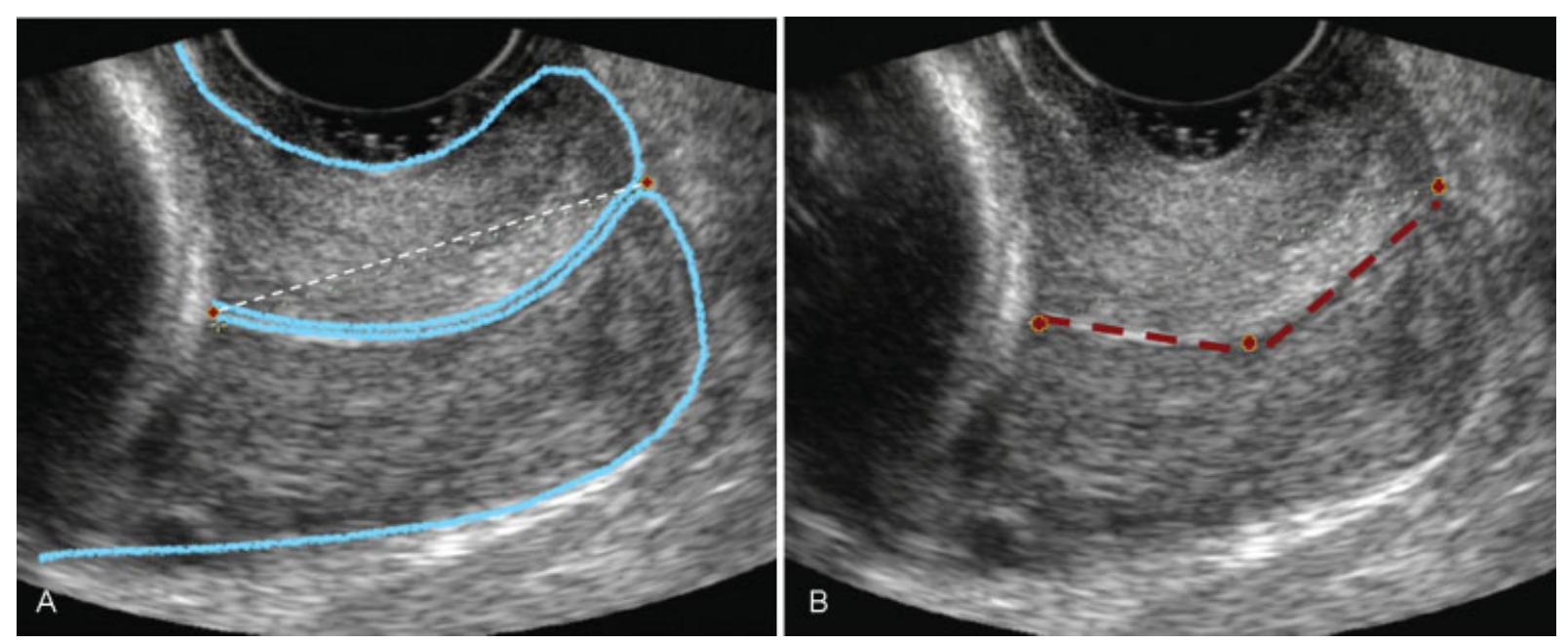

Fig. 1 Biometry of the uterine cervix using the continuous (A) and the segmented (B) techniques. 

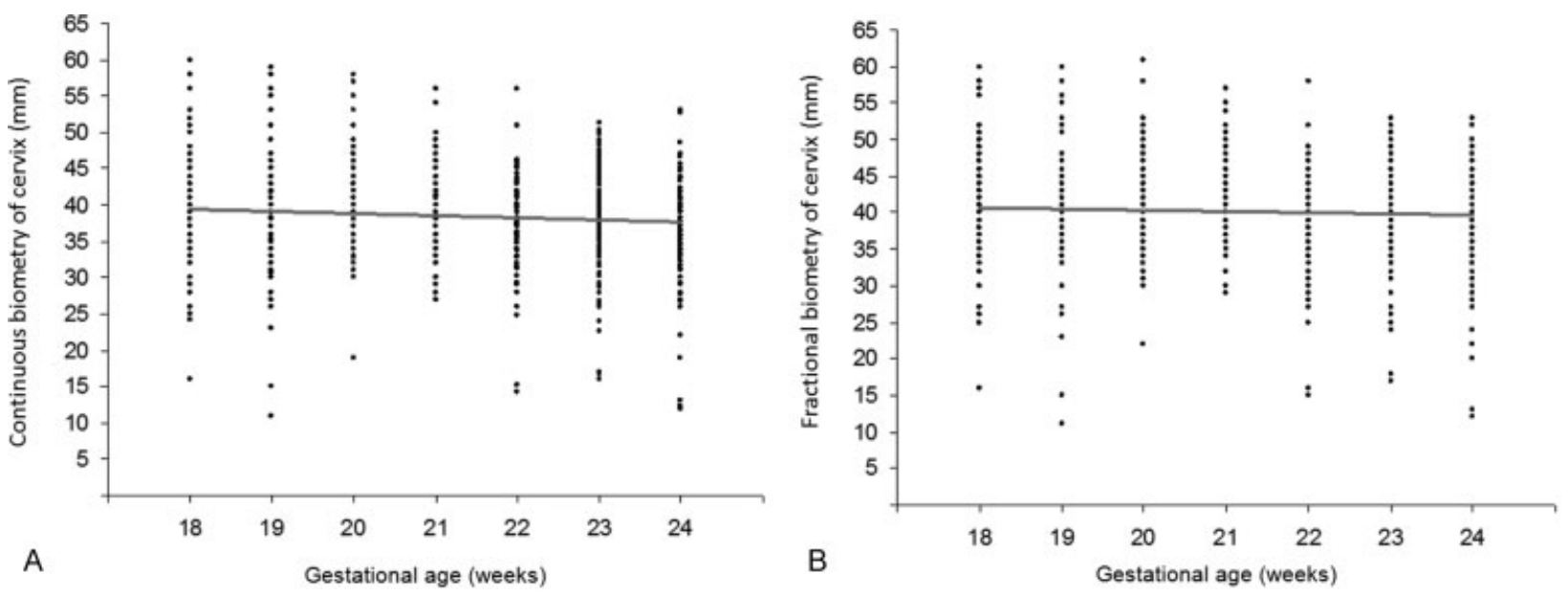

Fig. 2 Scatter plots of uterine cervical biometry, using the continuous (A) and the segmented (B) techniques, as a function of gestational age (B).

- Tables 1 and 2 show the percentiles 5, 10, 50, 90, and 95 of the cervical length, using the continuous and segmented techniques as a function of gestational age, respectively.

- Table 3 shows that there was a statistically significant difference between cervical lengths measured by both techniques at all gestational ages $(p<0.001)$, the mean difference being $1.7 \mathrm{~mm} \pm 2.6 \mathrm{~mm}$.

Of these 752 pregnant women, 390 (51.9\%) exhibited a curved uterine cervix and 362 (48.1\%) had a straight cervix. - Table 4 shows the distribution of curved and straight cervical morphology between 18 and 24 weeks of gestation.
According to - Fig. 3, there was a predominance of curved uterine cervix up to the $21^{\text {st }}$ week and a predominance of straight cervix after this gestational age.

\section{Discussion}

Until the late 1970s, the methods of assessing the uterine cervix consisted basically of subjective methods, namely direct observation through speculum examination and vaginal bidigital palpation. With the advent of the transvaginal ultrasound, in the early 1980s, the morphology and biometry

Table 1 Percentiles of uterine cervical length $(\mathrm{mm})$ using the continuous technique between 18 and 24 weeks of gestation

\begin{tabular}{|c|c|c|c|c|c|c|c|}
\hline \multirow[t]{2}{*}{ Percentiles } & \multicolumn{7}{|c|}{ Gestational age (weeks) } \\
\hline & 18 & 19 & 20 & 21 & 22 & 23 & 24 \\
\hline 5 & 26.0 & 26.0 & 31.3 & 30.0 & 26.4 & 27.5 & 22.0 \\
\hline 10 & 29.0 & 28.4 & 33.0 & 32.0 & 29.1 & 31.7 & 27.0 \\
\hline 50 & 39.0 & 38.0 & 39.0 & 40.0 & 38.3 & 38.7 & 37.3 \\
\hline 90 & 47.2 & 46.8 & 49.0 & 47.5 & 45.3 & 46.7 & 44.9 \\
\hline 95 & 52.6 & 53.8 & 56.3 & 48.7 & 46.2 & 47.9 & 46.8 \\
\hline$n$ & 87 & 91 & 86 & 84 & 83 & 211 & 110 \\
\hline
\end{tabular}

Table 2 Percentiles of uterine cervical length $(\mathrm{mm})$ using the segmented technique between 18 and 24 weeks

\begin{tabular}{|c|c|c|c|c|c|c|c|}
\hline \multirow[t]{2}{*}{ Percentiles } & \multicolumn{7}{|c|}{ Gestational age (weeks) } \\
\hline & 18 & 19 & 20 & 21 & 22 & 23 & 24 \\
\hline 5 & 26.0 & 26.0 & 31.3 & 30.0 & 27.2 & 31.0 & 23.1 \\
\hline 10 & 30.0 & 30.0 & 33.7 & 34.0 & 30.0 & 33.0 & 28.0 \\
\hline 50 & 41.0 & 39.0 & 40.0 & 42.0 & 40.0 & 41.0 & 39.0 \\
\hline 90 & 50.0 & 48.0 & 50.0 & 49.0 & 47.0 & 49.8 & 47.9 \\
\hline 95 & 54.4 & 53.8 & 56.2 & 51.7 & 48.8 & 51.0 & 49.0 \\
\hline$n$ & 87 & 91 & 86 & 84 & 83 & 211 & 110 \\
\hline
\end{tabular}


Table 3 Comparison between the continuous and the segmented techniques of cervical biometry between 18 and 24 weeks

\begin{tabular}{|l|l|l|l|l|l|l|l|}
\hline \multirow{2}{*}{ Cervical biometry } & \multicolumn{6}{|l|}{ Gestational age (weeks) } \\
\cline { 2 - 8 } & $\mathbf{1 8}$ & $\mathbf{1 9}$ & $\mathbf{2 0}$ & $\mathbf{2 1}$ & $\mathbf{2 2}$ & $\mathbf{2 3}$ & $\mathbf{2 4}$ \\
\hline Continuous (mm): mean (SD) & 38.77 & 38.19 & 40.19 & 39.83 & 37.60 & 38.61 & 36.27 \\
& $(7.45)$ & $(7.88)$ & $(6.73)$ & $(5.78)$ & $(6.87)$ & $(6.24)$ & $(7.56)$ \\
\hline Segmented (mm): mean (SD) & 40.20 & 39.51 & 41.02 & 41.63 & 39.00 & 40.82 & 38.12 \\
& $(7.81)$ & $(8.09)$ & $(6.63)$ & $(5.90)$ & $(6.93)$ & $(6.51)$ & $(7.97)$ \\
\hline Difference (segmented-continuous) & 1.42 & 1.32 & 0.83 & 1.81 & 1.40 & 2.21 & 1.85 \\
mean (SD) & $(2.36)$ & $(2.30)$ & $(2.15)$ & $(2.69)$ & $(2.92)$ & $(2.50)$ & $(3.37)$ \\
\hline Paired Student t-test (p) & $<0.001^{*}$ & $<0.001^{*}$ & $0.001^{*}$ & $<0.001^{*}$ & $<0.001^{*}$ & $<0.001^{*}$ & $<0.001^{*}$ \\
\hline
\end{tabular}

Abbreviation: SD, standard deviation.

Chi-square test for trend: $p=0.001^{*}$.

Table 4 Distribution of uterine cervical morphology between 18 and 24 weeks of gestation

\begin{tabular}{|c|c|c|c|c|c|c|c|}
\hline \multirow[t]{3}{*}{ Variables } & \multicolumn{7}{|c|}{ Gestational age (weeks) } \\
\hline & 18 & 19 & 20 & 21 & 22 & 23 & 24 \\
\hline & n (\%) & n (\%) & n (\%) & n (\%) & n (\%) & n (\%) & n (\%) \\
\hline Curved cervix & $58(66.7)$ & $51(56.0)$ & 46 (53.5) & $50(59.5)$ & $34(41.0)$ & $97(46.0)$ & 54 (49.1) \\
\hline Straight cervix & $29(33.3)$ & $40(44.0)$ & $40(46.5)$ & $34(40.5)$ & 49 (59.0) & $114(54.0)$ & $56(50.9)$ \\
\hline Total & 87 & 91 & 86 & 84 & 83 & 211 & 110 \\
\hline
\end{tabular}

of the uterine cervix have been increasingly studied, which led to a thorough investigations for the assessment of physiological changes during pregnancy. ${ }^{14}$

In the present study, by means of transvaginal ultrasound, we determined reference values for cervical length between 18 and 24 weeks of gestation; our sample was a Brazilian population at low risk for preterm labor, with a small variation within this gestational interval. Jafari-Dehkordi et $\mathrm{al}^{15}$ determined reference values for cervical length between 8 and 38 weeks of gestation using abdominal ultrasound in Iranian women. The mean cervical length did not show much difference between 18 and 24 weeks of gestation $(38.0 \mathrm{~mm})$. A recent study established conditional

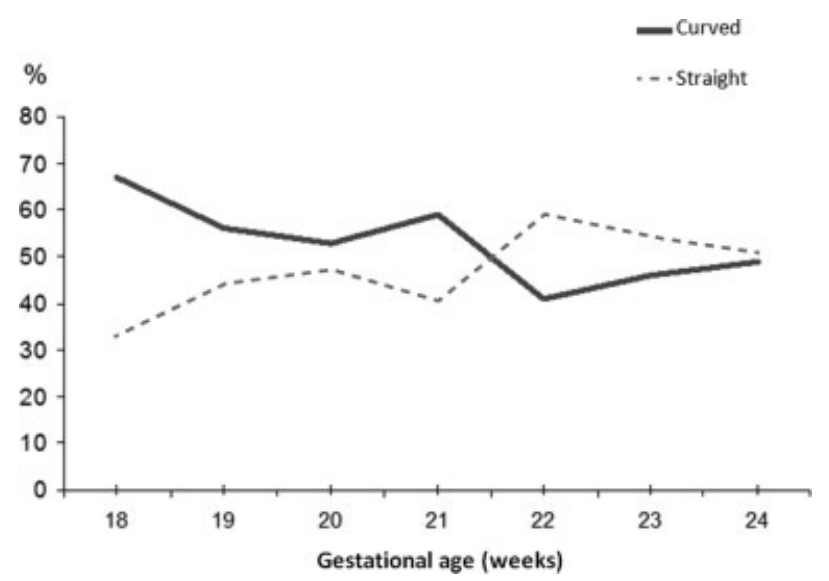

Fig. 3 Proportions of straight and curved morphology of the cervical canal between 18 and 24 weeks of gestation. intervals of cervical length using transvaginal ultrasound between 11 and 40 weeks in 4,397 Greek women. They observed that the best correlation between uterine cervical length and gestational age was a second-degree equation and the mean length between 18 and 24 weeks changed from 32.1 to $31.3 \mathrm{~mm}^{16}$ In a recent Brazilian study, Peixoto et $\mathrm{al}^{5}$ established a reference curve for cervical length in 996 singleton pregnancies between 20 and 24 weeks of gestation using the continuous technique of transvaginal ultrasound. The values did not vary significantly with gestational age and the mean length was $37 \mathrm{~mm}$ in this gestational interval. In the randomized controlled trial, the mean cervical length between 20 and 25 weeks of gestation was $33 \mathrm{~mm}$. This value was lower than the one found in our study $(38 \mathrm{~mm})$; however, there are several differences between both studies, such as low versus unselected population different number of cases (752 versus 24,620) and type of pregnancy (singleton versus singleton and twin). ${ }^{17}$

With regard to morphology, there was a predominance of curved uterine cervices. ${ }^{10,17}$ In the study by Yost et al, ${ }^{18}$ to determine parameters that could be predictors of preterm labor between 16 and 18 weeks of gestation, the curved cervical morphology predominated over the straight morphology (59\% versus $41 \%$ ); however, this type of morphology was shown to be a poor predictor. The results of this study are in line with our findings, namely the results of $51.9 \%$ of curved uterine cervix and $48.1 \%$ of straight cervix, thus confirming the predominance of the curved morphology up to the $21^{\text {st }}$ week. This morphology may be explained by local changes in collagen concentration in the uterine cervix during the first trimester of gestation. ${ }^{19}$ 
We used two measuring techniques to determine the cervical length: continuous and segmented. In women with a straight uterine cervix the measurements did not differ significantly; however, cervical biometry is hindered when the continuous technique is used in women with a curved cervix because the cervical length is often underestimated. According to the literature, the segmented technique, when performed along the endocervical canal, yields slightly higher yet more accurate values. ${ }^{10}$ The most adequate method to measure the uterine cervix when there is a bend seems to be the segmented technique; however, to prove this hypothesis it is necessary to compare the measurements to a gold standard or to establish the correlation between measurement by both techniques and the outcome of spontaneous preterm birth. So, in the interval between the $18^{\text {th }}$ and the $24^{\text {th }}$ weeks of gestation, the ideal gestational age for measuring the curved uterine cervix was the $21^{\text {st }}$ week using transvaginal ultrasound. At this stage, the phenomenon of uterine conversion has already occurred and the straight cervical morphology predominates; accordingly, biometric measurements are easier to perform and are more accurate.

As limitation, neither intra- nor inter-observer reproducibility were performed. However, all measurements were taken by only two experienced examiners, which could decrease this reproducibility. Furthermore, all cervical length measurements were performed by transvaginal route. In a previous study, transabdominal ultrasound measurement overestimated the mean cervical length by $8 \mathrm{~mm}$ among pregnant women with a short cervix and resulted in the underdiagnosis of $57 \%$ of cases. ${ }^{20}$

\section{Conclusion}

In conclusion, we determined reference values for uterine cervical length between 18 and 24 weeks of gestation in a Brazilian low-risk population using the continuous and segmented techniques. The values did not vary significantly with gestational age. The ideal gestational age for measuring cervical length was $\geq 21$ weeks.

\section{Contributors}

Andrade S. G. A., Andrade F. M., Araujo Júnior E., Pires C. R., Mattar R. and Moron A. F. contributed with the project conception, analysis and interpretation of data, critical review of the intellectual content and final approval of the version to be published.

\section{Conflicts to Interest \\ Authors declare no conflict of interest.}

\section{References}

1 Tsoi E, Akmal S, Geerts L, Jeffery B, Nicolaides KH. Sonographic measurement of cervical length and fetal fibronectin testing in threatened preterm labor. Ultrasound Obstet Gynecol 2006;27 (04):368-372

2 Hassan S, Romero R, Hendler I, et al. A sonographic short cervix as the only clinical manifestation of intra-amniotic infection. J Perinat Med 2006;34(01):13-19
3 Berghella V, Tolosa JE, Kuhlman K, Weiner S, Bolognese RJ, Wapner RJ. Cervical ultrasonography compared with manual examination as a predictor of preterm delivery. Am J Obstet Gynecol 1997; 177(04):723-730

4 Sonek JD, Iams JD, Blumenfeld M, Johnson F, Landon M, Gabbe S. Measurement of cervical length in pregnancy: comparison between vaginal ultrasonography and digital examination. Obstet Gynecol 1990;76(02):172-175

5 Peixoto AB, da Cunha Caldas TM, Alamy AH, Martins WP, Bruns RF, Araujo Júnior E. Reference values for the cervical length measurement in the second trimester of pregnancy using the transvaginal ultrasound in a large Brazilian population. Obstet Gynecol Sci 2016;59(04):303-306

6 Salomon LJ, Diaz-Garcia C, Bernard JP, Ville Y. Reference range for cervical length throughout pregnancy: non-parametric LMSbased model applied to a large sample. Ultrasound Obstet Gynecol 2009;33(04):459-464

7 Guzman ER, Walters C, Ananth CV, et al. A comparison of sonographic cervical parameters in predicting spontaneous preterm birth in high-risk singleton gestations. Ultrasound Obstet Gynecol 2001;18(03):204-210

8 Bagga R, Takhtani M, Suri V, Adhikari K, Arora S, Bhardwaj S. Cervical length and cervicovaginal HCG for prediction of pre-term birth in women with signs and symptoms of pre-term labour. J Obstet Gynaecol 2010;30(05):451-455

9 Jwala S, Tran TL, Terenna C, et al. Evaluation of additive effect of quantitative fetal fibronectin to cervical length for prediction of spontaneous preterm birth among asymptomatic low-risk women. Acta Obstet Gynecol Scand 2016;95(08):948-955

10 Gramellini D, Fieni S, Molina E, Berretta R, Vadora E. Transvaginal sonographic cervical length changes during normal pregnancy. J Ultrasound Med 2002;21(03):227-232, quiz 234-235

11 Rozenberg P, Gillet A, Ville Y. Transvaginal sonographic examination of the cervix in asymptomatic pregnant women: review of the literature. Ultrasound Obstet Gynecol 2002;19(03):302-311

12 Khalifeh A, Quist-Nelson J, Berghella V. Universal cervical length screening for preterm birth prevention in the United States. J Matern Fetal Neonatal Med 2017;30(12):1500-1503

13 Pedretti MK, Kazemier BM, Dickinson JE, Mol BW. Implementing universal cervical length screening in asymptomatic women with singleton pregnancies: challenges and opportunities. Aust N Z J Obstet Gynaecol 2017;57(02):221-227

14 Dodson MG, Deter RL. Definition of anatomical planes for use in transvaginal sonography. J Clin Ultrasound 1990;18(04):239-242

15 Jafari-Dehkordi E, Adibi A, Sirus M. Reference range of the weekly uterine cervical length at 8 to 38 weeks of gestation in the center of Iran. Adv Biomed Res 2015;4:115

16 Papastefanou I, Pilalis A, Kappou D, Souka AP. Cervical length at 11-40 weeks: unconditional and conditional longitudinal reference ranges. Acta Obstet Gynecol Scand 2016;95(12):1376-1382

17 Fonseca EB, Celik E, Parra M, Singh M, Nicolaides KH; Fetal Medicine Foundation Second Trimester Screening Group. Progesterone and the risk of preterm birth among women with a short cervix. N Engl J Med 2007;357(05):462-469

18 Yost NP, Owen J, Berghella V, et al; National Institute of Child Health and Human Development, Maternal-Fetal Medicine Units Network. Second-trimester cervical sonography: features other than cervical length to predict spontaneous preterm birth. Obstet Gynecol 2004;103(03):457-462

19 Gedikbasi A, Yücel B, Arslan O, Giris M, Gedikbasi A, Abbasoglu SD. Dynamic collagen changes in cervix during the first trimester and decreased collagen content in cervical insufficiency. J Matern Fetal Neonatal Med 2016;29(18):2968-2972

20 Hernandez-Andrade E, Romero R, Ahn H, et al. Transabdominal evaluation of uterine cervical length during pregnancy fails to identify a substantial number of women with a short cervix. J Matern Fetal Neonatal Med 2012;25(09):1682-1689 